\title{
High Voltage using DC-DC Switched Capacitor Converter for PV Application without Transformer
}

\author{
L.Chitra, Rohan Samuel Jayaseelan, Rohan Sunil
}

\begin{abstract}
In this paper, a DC-DC switched capacitor (SC) converter without using transformer is designed to achieve high voltage gain. Normally a transformer is used for AC-AC power conversion with step up or step down operation without changing the frequency. But it occupies more space due to its size and weight. Therefore, switched capacitor is used for achieving high voltage combine with converter, in order to avoid the transformer due to more expensive and losses. The traditional converter consists of more switches and stresses as well as losses with converter. In proposed converter, it uses fewer amounts of switches and gives high efficiency to increase the voltage gain. The current ripples are filtered that help to device life time and also reduce the electromagnetic interference. The designed converter is analyzed and the voltage is attained using MATLAB/Simulink.
\end{abstract}

Keywords: DC-DC converter, Transformer less switched capacitor (SC), and Voltage gain.

\section{INTRODUCTION}

Now a day, the Photo Voltaic (PV) energy applications are widely used all over the world. The solar energy is obtained from the sun through the PV cell and solar panels. There are several renewable energy sources available but particularly the solar energy source is extremely popular because of the lack of environmental problems related with the fuel based power generation and it will makes the solar energy more demand one. The solar energy advantages are pollution free, less maintenance, and the operation is noiseless. These merits makes the solar energy system most wanted for the past 25 years [1-2].

The demand of solar energy increasing day by day life mainly for the grid connected systems. The PV system is one of the very fast growing electricity over the worldwide and maximum power can be achieved by using the algorithms especially for the solar systems [3]. The variation of power from PV module can be regulated by using DC-DC inverters and the converters that perform the operation of buck and

Revised Manuscript Received on December 16, 2019

* Correspondence Author

Dr. L.Chitra, Associate Professor and Head, Department of EEE, Aarupadai Veedu Institute of Technology, Chennai, India.

Rohan Samuel Jayaseelan, Department of EEE, Aarupadai Veedu Institute of Technology, Vinayaka Mission's Research Foundation, Chennai, India.

Rohan Sunil, Department of EEE, Aarupadai Veedu Institute of Technology, Vinayaka Mission's Research Foundation, Chennai, India. boost. Converters are used to perform conversion of power. There are many converters to do such a works. The converter can perform both buck and gain operation [4-7]. Normally the converter has switching devices that partially allow the current and voltage according to the source of power and can convert to load [8-10].

The converters are used in power distribution and convert one form to another form of energy [11-13]. Through the converters only can achieve the grid requirement voltage because the renewable energy generation is far compare with grid. But to satisfy the grid requirement a transformer is used to step up the generation voltage and the transformer will occupies more place due to its size and weight and it has more losses such as heat loss, core loss etc.

In this paper, the high DC-DC voltage gain converter is used for compensates the DC voltage link that can be avoid the transformer utilization and converter must be able to work at low duty ratio to get high voltage gain ratio and to be performed under transient conditions. The boost converter has a behavior in nature of resonant for boost voltage process that extends the gain of DC voltage. The switched capacitor based converters are the common solution to attain high gain voltage. DC voltage gain will be enhanced as the switched capacitors are included with classic boost type. Clearly, the reactive elements are used to attain higher voltage.

\section{PROPOSED METHOD}

A single diode photo voltaic module of simple structure equivalent circuit is presented in this paper. The reliability is high in this structure and energy generation is easy to use. It has merits when compare with other structures. In this structure the parameters of the converters can be adjusted easily. The voltage-current equation is given by,

$$
\mathrm{I}_{\mathrm{PV}}=\mathrm{N}_{\mathrm{P}}\left\{\mathrm{I}_{\mathrm{ph}}-\mathrm{I}_{0}\left\{\exp \left(\mathrm{q}\left(\mathrm{V}_{\mathrm{PV}}\right) /\left(\mathrm{nNs} \mathrm{K}_{\mathrm{T}}\right)\right)\right\}\right\}
$$

A single diode of parallel and series resistance combinations are included in the equivalent circuit. The following circuit shows the PV model system in single diode. 


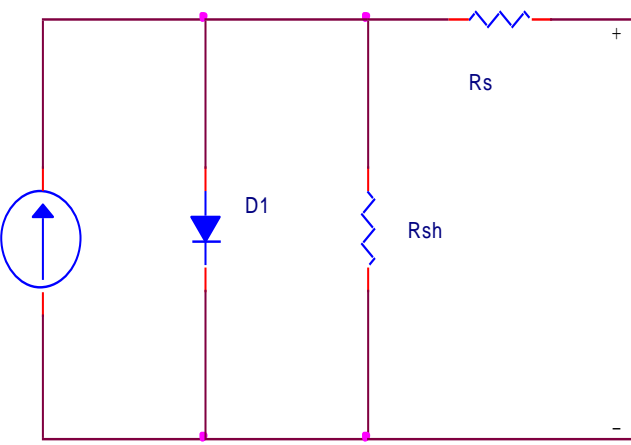

Fig. 1.A single diode model of PV system

In exchange of solar energy to extort highest power from the solar photo voltaic module, a technique named as maximum power point tracking is used to achieve high energy for applications. Nominal voltage and current in equation (2) is replaced by $V_{M P P}$ and $I_{\text {MPP }}$ is given by,

$$
\mathrm{I}_{\mathrm{MPP}}=\mathrm{N}_{\mathrm{P}}\left\{\mathrm{I}_{\mathrm{ph}}-\mathrm{I}_{0}\left\{\exp \left(\mathrm{q}\left(\mathrm{V}_{\mathrm{MPP}}\right) /\left(\mathrm{nNs} \mathrm{K}_{\mathrm{T}}\right)\right)\right\}\right\}
$$

\section{A. Switched Capacitor Converter}

The switched capacitor is most popular technique for boosting the voltage. This circuit consists of energy storage elements like capacitors, inductors and combined with switching devices to get the high voltage. Switched capacitor circuit shown in below fig. 2 .

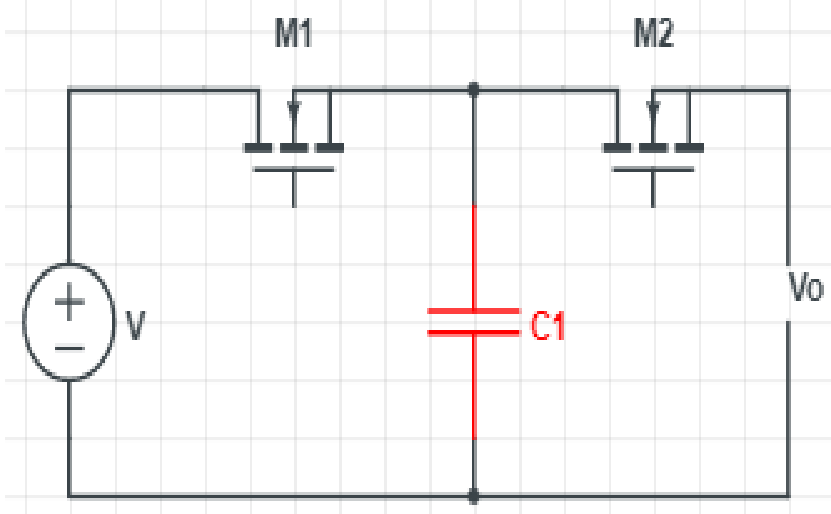

Fig. 2.Fundamental switched capacitor circuit

The stored energy is transferred from one capacitor to another one by the appropriate switching action. The switched capacitor is used in power conversion on chip that in low power applications. In this switched capacitor, the high voltage gain circuit is simple due to fewer numbers of components and simple control methods. The proposed design system is shown in fig. 3 .

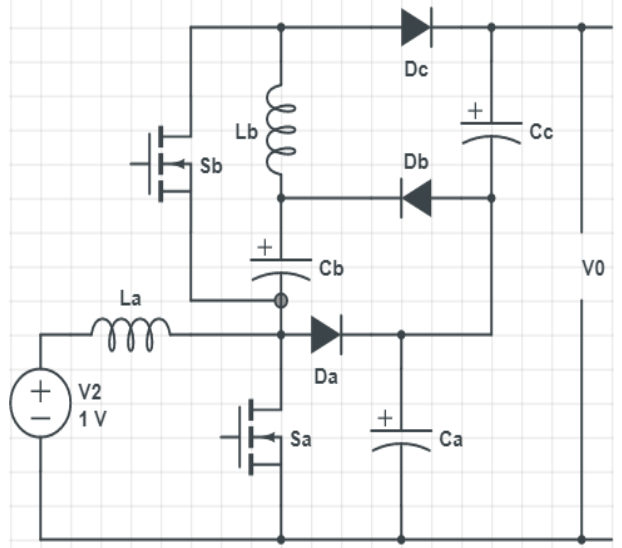

Fig. 3.Proposed the transformer-less switched capacitor converter

The proposed circuit consists of two active switches named as, $\mathrm{Sa}$ and $\mathrm{Sb}$ and the inductor and capacitor are used to achieve the boost operation, and further the generated energy will be stored in another capacitor and inductor. The energy stored elements are controlled by the active switches. Here three diodes are used to represent the pulses of active switches and the diodes are $\mathrm{Da}, \mathrm{Db}$ and $\mathrm{Dc}$. The operation is classified into two modes: continuous conduction mode (CCM) and discontinuous conduction mode (DCM).

\section{B. Continuous Mode}

In the continuous mode, there are three modes. In the first mode, $\mathrm{Sa}$ and $\mathrm{Sb}$ are on state and $\mathrm{Db}$ is turned on. The inductor $\mathrm{La}$ energized but the $\mathrm{Ca}$ gets discharged. This process is known as regenerative step up operation. The voltage across the inductors is given below equation (3) and in second mode, $\mathrm{Sa}$ is turned on and $\mathrm{Da}$ and $\mathrm{Db}$ are on state. The inductor $\mathrm{La}$ and capacitor $\mathrm{Cb}$ gets discharged to load. The voltage across the inductors is given in below equation (4)

$V_{L a}=V$

$V_{L b}=\frac{V_{S}}{\left(1-D_{a}\right)}$

$V_{L a}=V_{S}$

$V_{L b}=-\left[\frac{V_{0}\left(1-D_{a}\right)-V_{S}}{\left(1-D_{a}\right)}\right]$

In the third mode, both switches that S1 and S2 are in off state. Then the diodes Da and Dc are turned on. The capacitor $\mathrm{Cb}$ gets discharged and the inductors $\mathrm{La}$ and $\mathrm{Lb}$ are stored energy from source. The voltage across the inductors is given by, 
$V_{L a}=-\frac{V_{S} D_{a}}{\left(1-D_{a}\right)}$

$V_{L b}=-\left[\frac{V_{0}\left(1-D_{a}\right)-2 V_{S}}{\left(1-D_{a}\right)}\right]$

\section{Discontinuous Mode}

In this, there are three modes, mode1, mode 2 and mode 3. In mode 1 , the inductors $\mathrm{La}$ and $\mathrm{Lb}$ gets charged. The direction of current is same as continuous conduction mode. In mode 2 , the process is similar to the operation of mode 1. Similarly in mode 3 the inductor La gets charged and the capacitors $\mathrm{Ca}$ and $\mathrm{Cb}$ are discharged and supply the current to load of system and it is similar to mode 2 .

\section{SIMULATION AND RESULTS}

The proposed system consists of PV fed switched capacitor DC-DC converter to attain enhanced high voltage. It is implemented in MATLAB/Simulink. The proposed simulink system consists of two MOSFET switches ( $\mathrm{Sa}$ and $\mathrm{Sb}$ ), three diodes ( $\mathrm{Da}, \mathrm{Db}$, and $\mathrm{Dc}), 3$ capacitor $(\mathrm{Ca}, \mathrm{Cb}$, and $\mathrm{Cc})$, and two inductor ( $\mathrm{La}$ and $\mathrm{Lb}$ ) for boosting the voltage from the PV. The Simulink design of the proposed system is represented in fig. 4 .

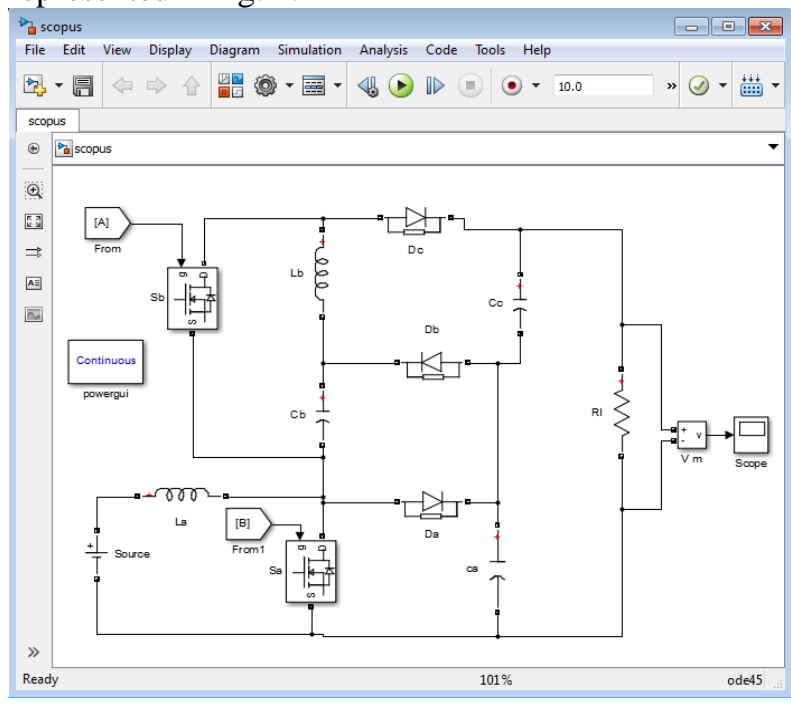

Fig. 4.proposed system Simulink model

Input voltage of the PV system is $12 \mathrm{~V}$ which is represented in fig. 4.

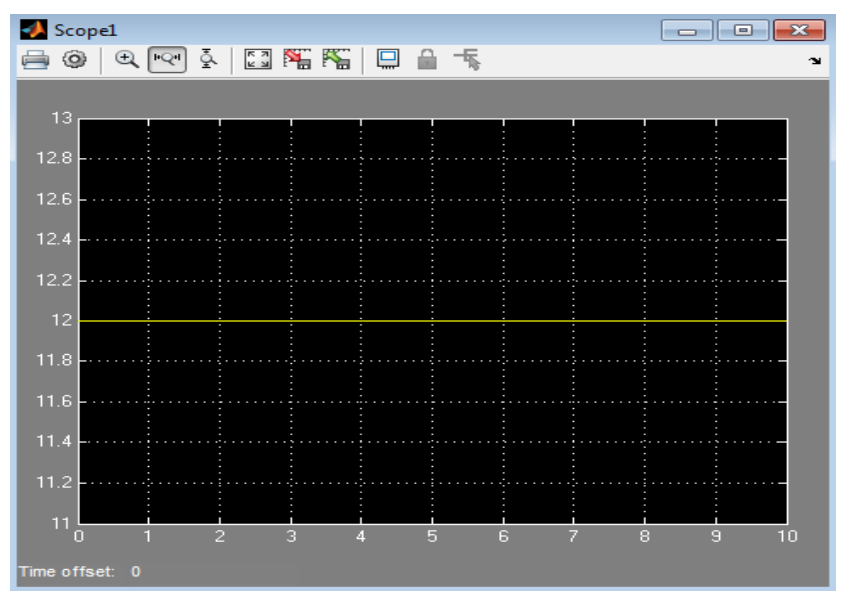

Fig. 5.Input dc voltage $12 \mathrm{~V}$

The output voltage of the system is shown in fig. 5. The system output voltage is $104 \mathrm{~V}$. The purpose of this work is to boost the voltage ratio source voltage. It boosts the voltage part of $8.4 \mathrm{~V}$.

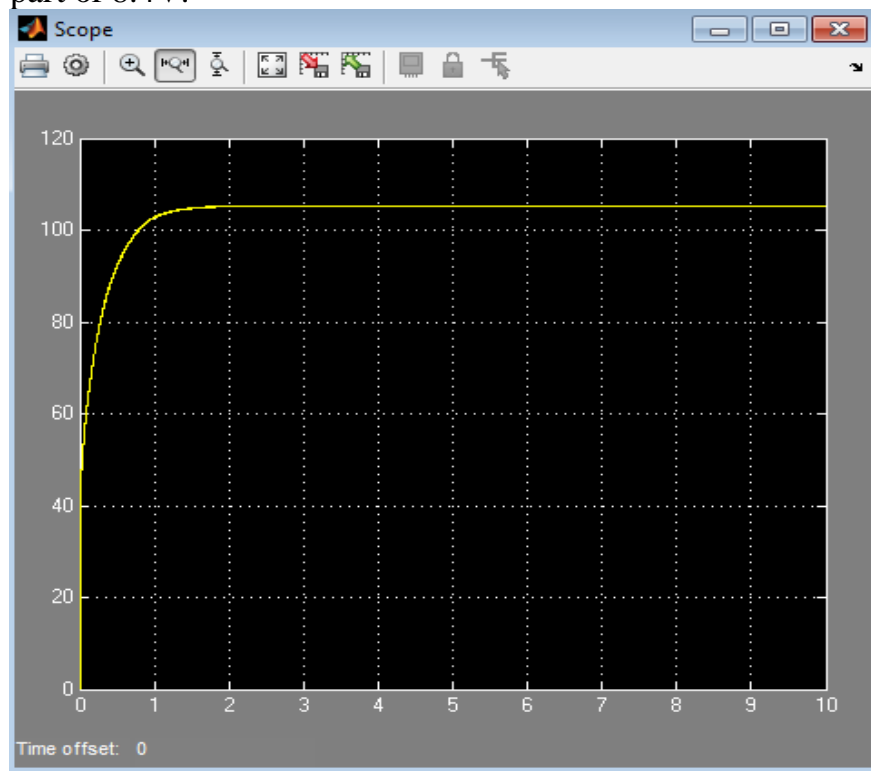

Fig. 6.Output voltage gain

Fig. 6 shows that value of current output with respect to $R$ load is $0.12 \mathrm{~A}$

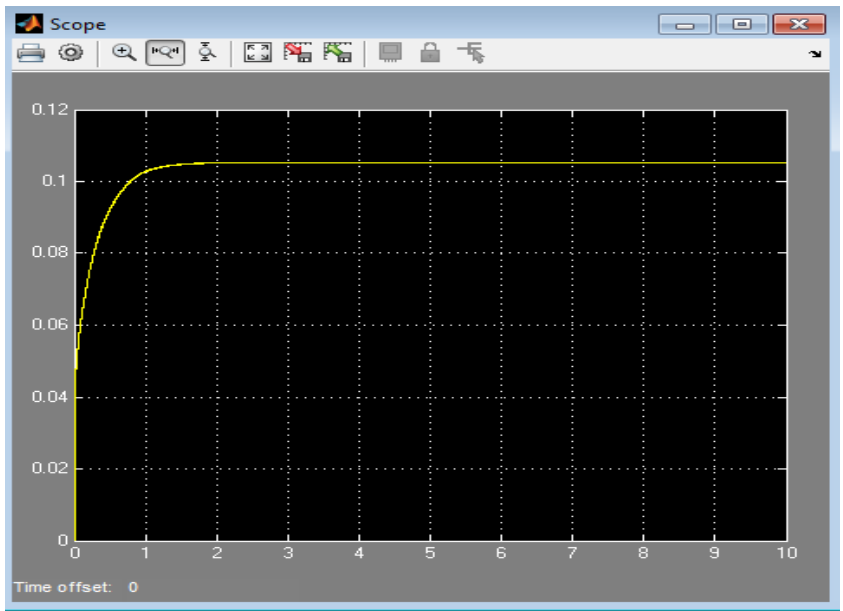

Fig. 7.Output current 


\section{CONCLUSION}

For obtaining high voltage gain this paper proposed a switched capacitor and DC-DC high gain converter combination. The aim of this paper is achieved through using switched capacitor in solar applications. Thereby, the utilization of transformer can be avoided and the losses are eliminated. The proposed converter gives high efficiency using switched capacitor and the switching losses are reduced by operating at low duty cycles in system. A high voltage gain of around $104 \mathrm{~V}$ is achieved as input voltage is $12 \mathrm{~V}$. The high voltage gain and current are verified through the implementation of the system in MATLAB/Simulink.

\section{REFERENCES}

1. P. Sharma, and V. Agarwal, "Exact maximum power point tracking of grid-connected partially shaded PV source using current compensation concept," IEEE Transactions on Power Electronics, vol. 29, no. 9, pp. 4684-92,2013.

2. S.Siva, "Automatic solar tracker, "International Journal of MC SquareScientific Research, vol.8, no.1, 2016

3. S. P. Thiruvadi, and S. Bhuvaneshwari, "Hybrid PV-Wind-Battery Based System for Household Applications Using Dc-Dc Converter,"

4. S. Jain, and V. Agarwal, "A single-stage grid connected inverter topology for solar PV systems with maximum power point tracking," 2007.

5. J. W. Baek, M. H. Ryoo, T.J. Kim, D. W. Yoo, and J. S. Kim, "High boost converter using voltage multiplier," In31st Annual Conference of IEEE Industrial Electronics Society, pp. 6, 2005.

6. R. K. Mudi, and N. R. Pal, "A self-tuning fuzzy PI controller," Fuzzy sets and systems, vol. 115, no. 2, pp. 327-38, 2000.

7. J. W. Choi, and S. C. Lee, "Anti windup strategy for PI-type speed controller," IEEE Transactions on Industrial Electronics, vol. 56, no. 6, pp. 2039-46, 2009

8. J. B. He, Q. G. Wang, and T. H. Lee, "PI/PID controller tuning via LQR approach," Chemical Engineering Science, vol.55, no. 13, pp. 2429-39, 2000

9. H. Sira-Ramirez, "Nonlinear PI controller design for switch mode DC-to-DC power converters," IEEE Transactions on Circuits and Systems, vol. 38, no. 4, pp. 410-417, 1991.

10. J. K. Seok, J. K. Lee, and D. C. Lee, "Sensorless speed control of non-salient permanent-magnet synchronous motor using rotor-position-tracking PI controller," IEEE Transactions on Industrial Electronics, vol. 53, no. 2, pp. 399-405, 2006.

11. H.Gholizadeh, A. Sarikhani, and M. A. Hamzeh, "Transformer less quadratic buck-boost converter suitable for renewable applications," IEEE 10th International Power Electronics, Drive Systems and Technologies Conference (PEDSTC), pp. 470-474, 2019

12. N. Elsayad, H. Moradisizkoohi, and O. A. Mohammed, "A Single-Switch Transformer less DC--DC Converter with Universal Input Voltage for Fuel Cell Vehicles: Analysis and Design," IEEE Transactions on Vehicular Technology, vol. 68, no. 5, pp.4537-4549, 2019.

13. V.B. Manimaran, "Design and Implementation Of Solar-Wind Combo For Hybrid Energy Application," International Journal of MC Square Scientific Research, vol.5, no.1 Nov 2013, pp. 37-42.

\section{AUTHORS PROFILE}

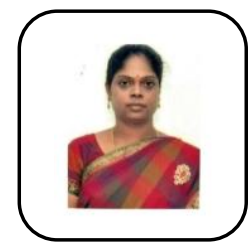

L. Chitra is an Associate Professor and Head in the department of EEE at Aarupadai Veedu Institute of Technology. She received her Bachelor Degree in Electronics and Instrumentation Engineering. She received her Master's Degree in Power Electronics and Drives in Anna University. She completed her $\mathrm{PhD}$ in Sathyabama Institute of Science and Technology in the field of Micro Electro Mechanical Systems for sensor design. Her research area includes MEMS, Renewable Energy, Process control, Sensors and Smart Sensors. She has published more than fifteen papers in International Conferences and Journals. She has a teaching experience of more than 18 years. She has received MNRE fund of Rs.1,50,000 for National Conference on Emerging Trends in New Renewable Energy Sources in the year 2014. She has also received a fund of Rs.1,00,000 from Unnat Bharat Abhiyan for Mobile Reverse osmosis based water purification system using Solar PV source for rural India in year 2019. She has also received a fund of Rs.50,000 from Unnat Bharat Abhiyan for DC Micro Grid based Solar PV generation to supply power to street lamp and common utilities in a village.

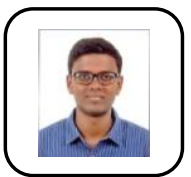

Rohan Samuel Jayaseelan, has completed his Bachelor's Degree at Aarupadai Veedu Institute of Technology, Vinayaka Mission's Research Foundation, Chennai. He is one of the notable student in his college, for his interest in the field of PLC and Mechantronics systems. He has worked on many projects related to Renewable Energy, PLC, Robotics, etc., His current research interests include power electronics, renewable energy, Automation etc.

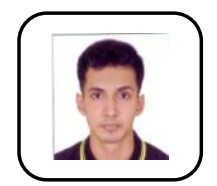

Rohan Sunil has completed his Bachelor's Degree at Aarupadai Veedu Institute of Technology, Vinayaka Mission's Research Foundation, Chennai. He has worked on many projects related to Renewable Energy, PLC and its applications, etc.,. He is one of the notable student in his college for his interest in the field of Automation and Renewable Energy. His current research interests include power electronics, renewable energy, SCADA, PLC, Converters etc., 